\title{
PROPRIEDADES MECÂNICAS DE GÉIS SIMPLES E MISTOS POR REDES NEURAIS ARTIFICIAIS
}

\author{
B. C. F. CARVALHO*, T. D. MARTINS e F. A. PERRECHIL \\ Universidade Federal de São Paulo, Departamento de Ciências Exatas e da Terra \\ E-mail para contato: biacarvalh@hotmail.com
}

\begin{abstract}
RESUMO - A previsibilidade de propriedades mecânicas dos géis de caseinato de sódio com ou sem adição de polissacarídeos foi estudada por meio da aplicação das redes neurais artificiais. A melhor configuração de rede encontrada foi obtida por meio do treinamento de diversas estruturas com 10 a 30 neurônios na camada oculta, inserindo-se para os dados de entrada valores numéricos de concentração da proteína caseinato de sódio e polissacarídeos, tipo de polissacarídeo (inulina, carragena e LBG), temperatura de gelificação e razão glucona- $\delta$-lactona (GDL)/caseinato. Para os dados de saída, foram inseridos valores de tensão na ruptura, deformação na ruptura e módulo de Young. A melhor configuração encontrada foi a 5-20-3, que se mostrou adequada para modelar os parâmetros de interesse.
\end{abstract}

\section{INTRODUÇÃO}

As proteínas e os polissacarídeos são dois tipos de biopolímeros responsáveis pela estrutura, textura e estabilidade dos alimentos devido às suas propriedades funcionais (Doublier et al., 2000). O caseinato de sódio, em especial, é amplamente utilizado pela indústria de alimentos como fonte de proteína devido às suas propriedades de emulsificação e capacidade de gelificação (Braga et al., 2006). Ele é capaz de produzir géis em pH próximo ao seu ponto isoelétrico. A acidificação dos sistemas pode ser realizada pela adição de glucona- $\delta$-lactona (GDL), que é hidrolisada em ácido glucônico com o tempo, levando a uma redução no valor do $\mathrm{pH}$ (Takeuchi e Cunha, 2008).

Apesar do grande número de estudos sobre a gelificação de proteínas com ou sem a presença de polissacarídeos e das propriedades mecânicas dos géis (Braga et al., 2006; Perrechil et al., 2009; Picone et al., 2011), existem poucos trabalhos que desenvolveram modelos matemáticos que correlacionem o seu comportamento mecânico-estrutural e os modelos encontrados para esse tipo de sistema complexo são ainda muito limitados (Perrot $e t$ al., 2011; Foucquier et al., 2012).

As Redes Neurais Artificiais (RNA) representam um novo paradigma metodológico no campo da Inteligência Artificial, e têm sido empregadas com sucesso para a descrição e modelagem de processos nas mais diversas áreas do conhecimento, desde economia, administração e até controle de processos industriais complexos (Klassen, 2008). A estrutura da rede neural artificial consiste basicamente por uma camada de entrada, camadas ocultas ou intermediárias e uma camada de saída. Cada camada, composta por neurônios ajustáveis, gera o modelo neural que é obtido por meio da determinação de seus pesos sinápticos. 
Matematicamente, os valores de ativação para cada neurônio são a soma das informações recebidas multiplicadas pelos pesos correspondentes. Através de funções lineares ou nãolineares a saída do elemento de processamento é determinada (Braga et al., 2000).

A aplicação de redes neurais tem sido empregada com sucesso na modelagem de propriedades mecânicas de géis proteicos (He e Mu, 2013) e representa uma alternativa viável e prática na busca de resultados confiáveis para a previsibilidade de dados em forma de uma série de saídas de interesse.

O principal objetivo desse trabalho consistiu na obtenção de uma RNA, composta por uma única camada intermediária, capaz de prever propriedades mecânicas de tensão na ruptura, deformação e módulo de Young de géis proteicos ou mistos (compostos por proteína e polissacarídeo). Para isso, foram testadas diversas estruturas com diferentes números de neurônios a fim de se obter a melhor rede.

\section{MATERIAIS E MÉTODOS}

Para análise da influência da arquitetura da rede neural sobre a precisão das respostas, partiu-se da inserção de dados para uma rede que pudesse prever três variáveis de saída: tensão na ruptura, deformação na ruptura e módulo de Young. Essas variáveis foram obtidas a partir das propriedades mecânicas dos géis sob compressão uniaxial a $80 \%$ de deformação e velocidade de compressão de $1 \mathrm{~mm} / \mathrm{s}$.

Como variáveis de entrada, os parâmetros selecionados relacionados à composição dos géis foram: concentração de caseinato de sódio, tipo de polissacarídeo, sendo eles: inulina, carragena e goma jataí (LBG), concentração do polissacarídeo, temperatura de gelificação com GDL e razão GDL/caseinato. Para as variáveis não numéricas, como é o caso do tipo de polissacarídeo, foi preciso estabelecer uma relação numérica para cada uma. Assim, para esses casos, a entrada da RNA era: sem polissacarídeo: 0, inulina: 1, carragena: 2, LBG: 3.

Todos os dados experimentais foram baseados em artigos científicos de um mesmo grupo de pesquisa, os quais utilizaram o mesmo equipamento e mesma metodologia para análise das propriedades mecânicas dos géis (Ribeiro et al., 2004; Braga et al., 200; Perrechil et al., 2009; Picone et al., 2011).

As simulações foram realizadas utilizando-se o toolbox de RNAs do software MatLab (B 2015, ao passo que o algoritmo utilizado foi o de Levemberg-Marquadt. A estrutura geral da rede selecionada foi: uma camada oculta, em que a função de ativação utilizada foi a tangente sigmoidal e variou-se o número de neurônios na camada intermediária entre 10 e 30 . De todos os 79 dados experimentais disponíveis, três conjuntos foram divididos aleatoriamente, sendo $70 \%$ para treinamento, $15 \%$ para validação e $15 \%$ para teste (segunda validação). Ao longo do treinamento o programa analisa a função objetivo, que neste trabalho foi a diferença quadrática entre o valor experimental e o calculado pela RNA, para os três conjuntos de dados. Um dos critérios de parada para o algoritmo foi o Número de Épocas igual a 1000, enquanto o critério principal foi a minimização da função objetivo, que era a diferença quadrática dos erros. Por fim, foram comparados os resultados gerados pela RNA com os dados experimentais coletados e então calculados os erros para cada variável de saída. 
Na Tabela 1 é apresentada a faixa de valores dos dados de entrada utilizados para o treinamento da RNA.

Tabela 1 - Parâmetros de entrada da rede para o treinamento

\begin{tabular}{ccccc}
\hline $\begin{array}{c}\text { Concentração } \\
\text { proteína }(\%)\end{array}$ & $\begin{array}{c}\text { Concentração } \\
\text { polissacarídeo } \\
(\%)\end{array}$ & $\begin{array}{c}\text { Tipo de } \\
\text { polissacarídeo }\end{array}$ & $\begin{array}{c}\text { Temperatura } \\
\left({ }^{\circ} \mathrm{C}\right)\end{array}$ & $\begin{array}{c}\text { Razão } \\
\text { GDL/caseinato }\end{array}$ \\
\hline $0-10$ & $0-5,1$ & $0-3$ & $6-90$ & $0,135-0,180$ \\
\hline
\end{tabular}

\section{RESULTADOS E DISCUSSÃO}

Os dados experimentais obtidos foram modelados utilizando diferentes estruturas de RNAs. Na Tabela 2 são apresentados os valores de função objetivo, bem como o Número de Épocas e $\mathrm{r}^{2}$ para cada uma das estruturas testadas. Nessa tabela, entende-se a estrutura da RNA da seguinte forma: 5 neurônios na camada de entrada (representando as 5 variáveis de entrada) e 3 neurônios na camada de saída (representando as 3 variáveis de saída). A camada intermediária da RNA foi a que teve seu número de neurônios modificado conforme os testes avaliados.

Tabela 2 - Valores de função objetivo, Número de Épocas e $\mathrm{r}^{2}$ para as diferentes estruturas das redes

\begin{tabular}{ccccc}
\hline Estrutura & $\begin{array}{c}\text { Número de } \\
\text { Épocas }\end{array}$ & Função objetivo & $\mathrm{r}^{2}$ treinamento & $\mathrm{r}^{\mathbf{2}}$ validação \\
\hline $5-10-3$ & 15 & 5,82 & 0,997 & 0,985 \\
$5-15-3$ & 10 & 7,79 & 0,974 & 0,991 \\
$\mathbf{5 - 2 0 - 3}$ & $\mathbf{1 0}$ & $\mathbf{4 , 4 3}$ & $\mathbf{0 , 9 9 3}$ & $\mathbf{0 , 9 9 6}$ \\
$5-25-3$ & 16 & 9,04 & 0,993 & 0,994 \\
$5-30-3$ & 94 & 8,94 & 0,996 & 0,991 \\
\hline
\end{tabular}

Analisando-se a Tabela 2, pode-se notar que para as estruturas de redes avaliadas, as configurações atingiram bons resultados, com valores de $\mathrm{r}^{2}$ próximos a 1 .

Para a escolha da melhor estrutura, se levou em consideração maior $\mathrm{r}^{2}$ e menor valor da função objetivo. Sendo assim, entre as configurações testadas, a melhor estrutura de rede que apresentou esses parâmetros foi a 5-20-3. Nessa rede, os valores de $\mathrm{r}^{2}$ foram os mais próximos de 1, além de apresentar o menor valor da função objetivo. A Figura 1 apresenta os gráficos construídos, para cada variável de saída, comparando-se os valores da RNA e os valores experimentais para a melhor configuração de estrutura de rede encontrada.

Analisando-se a Figura 1, é possível observar que o treinamento foi bastante efetivo para o módulo de Young e a tensão na ruptura, já que a forma do gráfico é praticamente uma reta a $45^{\circ}$, o que indica que os dados gerados pela RNA e os experimentais são quase equivalentes. Em contrapartida, para a deformação na ruptura, os resultados não foram tão eficazes, já que a quantidade de pontos sobre a reta foi menor. 
Para melhor avaliar o desempenho da RNA 5-20-3, foram calculados os erros para cada variável, obtidos comparando-se os valores de dados experimentais utilizados para treinar a rede com os valores de dados fornecidos pela RNA. A Figura 2 apresenta os gráficos construídos a partir dos erros percentuais, calculados ponto a ponto, para a melhor configuração avaliada.

A partir da análise dos gráficos, observa-se que os erros mais significativos encontramse para os valores mais baixos de cada uma das propriedades mecânicas dos géis, e são menores especialmente para os valores do módulo de Young e para a deformação na ruptura. Os erros médios para o módulo de Young, deformação na ruptura e tensão de ruptura são respectivamente $12,16 \%, 24,96 \%$ e $30,32 \%$.

Figura 1 - Valores preditos versus valores experimentais para a estrutura 5-20-3.
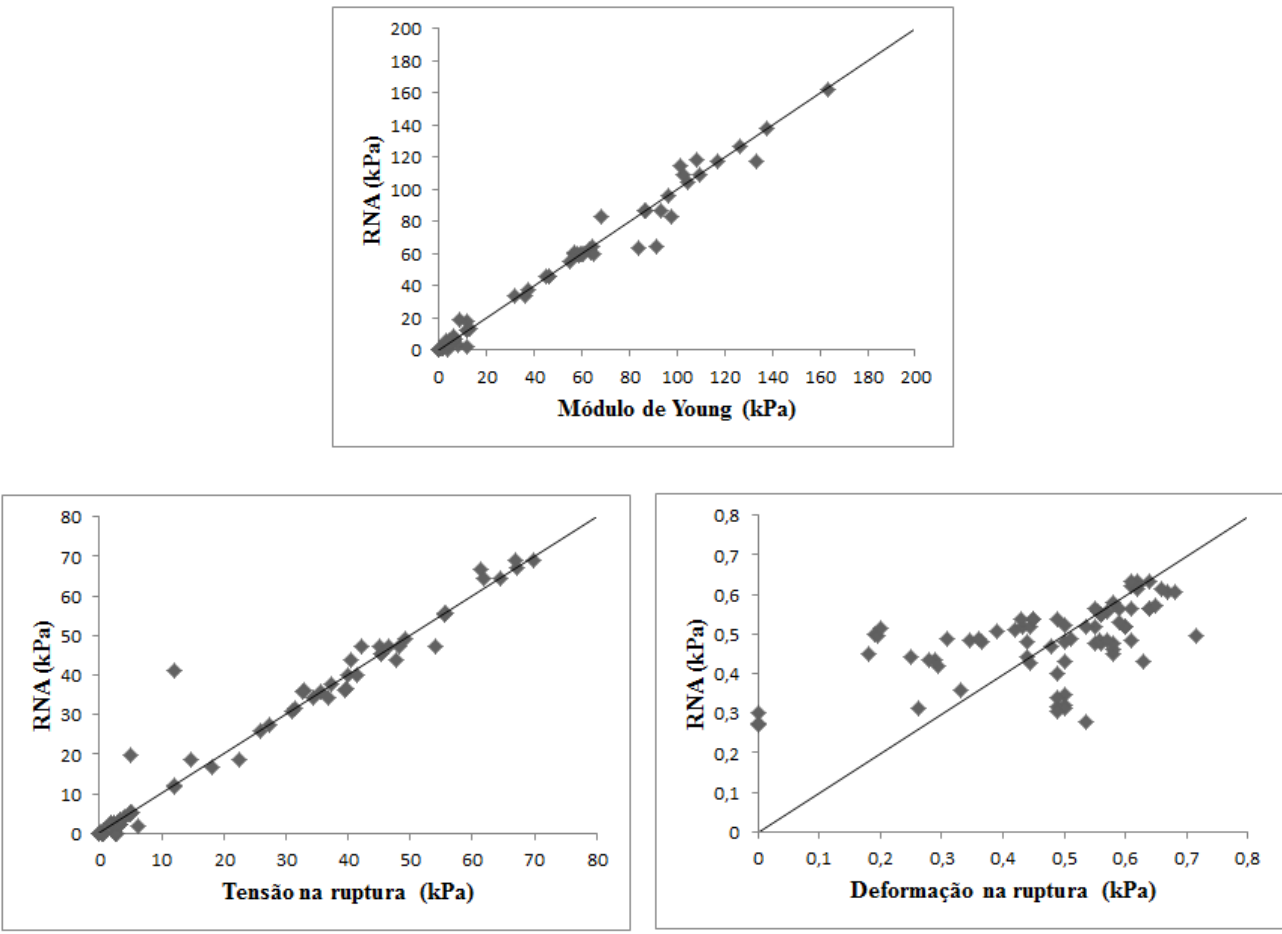

He e Mu (2013) aplicaram RNA para a predição das propriedades físicas de géis de proteínas do soro com a variação da pressão, concentração de proteína e concentração de açúcar. Esses autores obtiveram valores de $r^{2}$ de 0,998 a 0,999 e erros médios na faixa de 4,2 a $4,7 \%$, indicando uma boa predição do modelo encontrado.

Imagina-se que, para melhoria dos erros encontrados no presente trabalho, a normalização dos dados de entrada e saída possam ser uma solução. Quando se tem valores numéricos muito baixos sendo apresentados à rede, corre-se o risco do erro numérico ser maior, muitas vezes, do que o próprio dado. Sendo assim, a normalização pode ser uma alternativa para suprir esse problema. Além disso, sugere-se um estudo mais aprofundado dos erros, identificando quais os pontos que estão muito fora da previsão. Isso porque os erros podem estar relacionados ao padrão experimental. 
Apesar dos erros apontados, este trabalho mostrou que uma única RNA pode ser uma ferramenta poderosa na predição do comportamento mecânico-estrutural de géis simples e mistos.

Figura 2 - Erro percentual de cara ponto experimental para a estrutura 5-20-3.
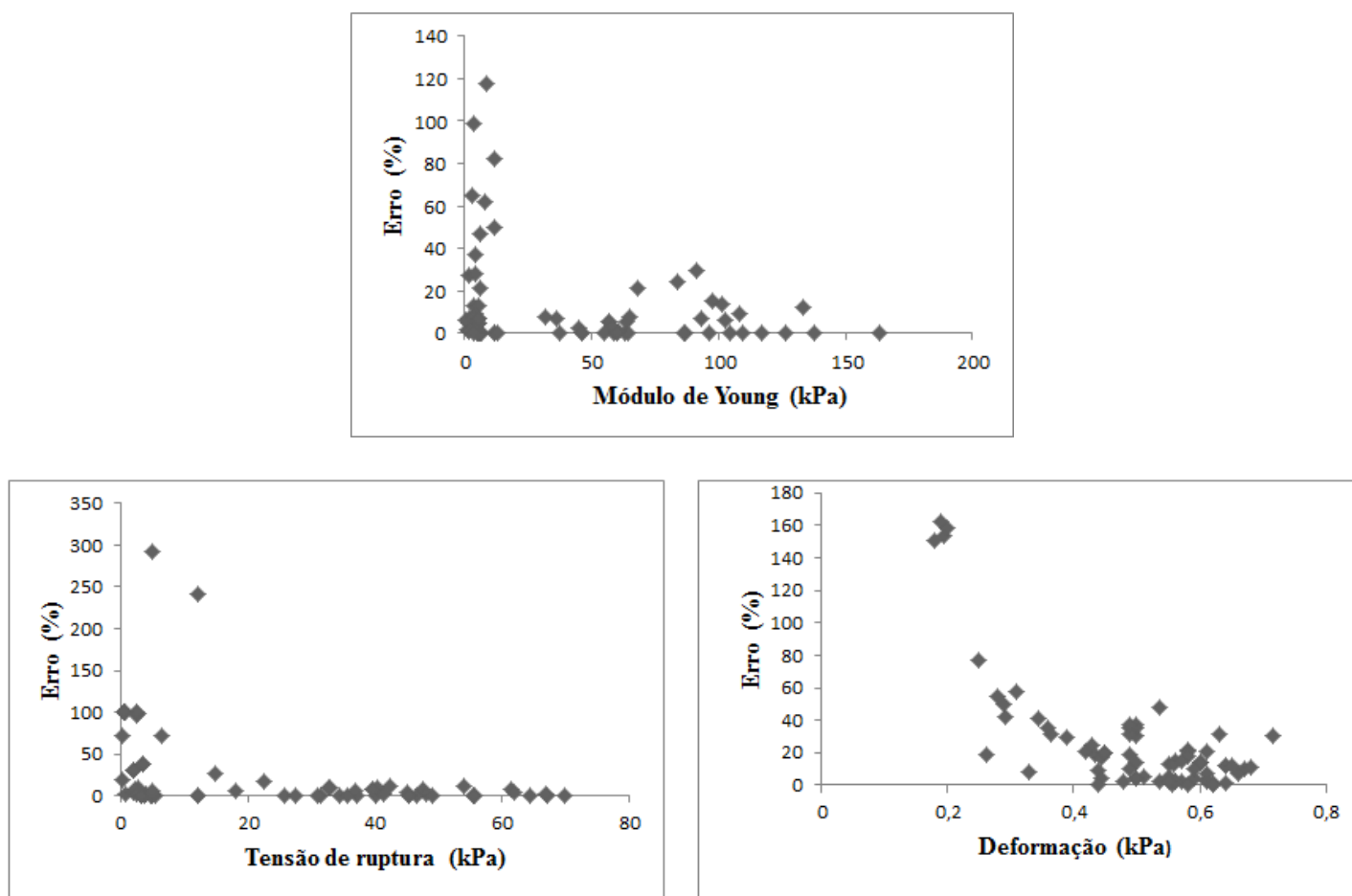

\section{CONCLUSÃO}

O estudo de RNAs tendo em vista a previsibilidade de propriedades mecânicas de géis simples e mistos se mostrou mais eficaz com a configuração 5-20-3. Nessa rede contendo uma camada oculta, os valores de $\mathrm{r}^{2}$ foram os mais próximos de 1 e com o menor valor da função objetivo.

Apesar dos erros mais significativos para os menores valores dos dados de saída ao se comparar os valores experimentais com os fornecidos pela RNA, o treinamento da rede foi bastante efetivo para o módulo de Young e a tensão de ruptura, demonstrando assim a capacidade de aprendizado das RNAs.

A aplicação das redes neurais na modelagem matemática das propriedades mecânicoestruturais de géis de proteína e polissacarídeos se mostrou vantajosa ao apresentar bons resultados de maneira rápida, prática e precisa, além de representar uma alternativa a métodos convencionais. Além disso, esse tipo de modelagem permite a avaliação simultânea de diferentes variáveis, sendo uma ferramenta com elevado potencial para aplicação em sistemas alimentícios complexos. 


\section{AGRADECIMENTOS}

Agradecemos ao CNPq pelo suporte financeiro ao desenvolvimento desse trabalho.

\section{REFERÊNCIAS}

BRAGA, A. P.; CARVALHO, A.; LUDERMIR, T. B. Redes neurais artificiais: teoria e aplicações. Rio de Janeiro: Livros Técnicos e Científicos, 2000.

BRAGA, A. L. M.; CUNHA R. L. The effect of the glucono- $\delta$-lactone/caseinate ratio on sodium caseinate gelation. International Dairy Journal, v. 16, p.389-398, 2006.

DOUBLIER, J. -L., GARNIER, C., RENARD, D., \& SANCHEZ, C. Protein-polysaccharide interactions. Current Opinion in Colloid and Interface Science, v. 5, p. 202-214, 2000.

FOUCQUIER, J.; CHANTOISEAU, E.; LE FEUNTEUN, S.; FLICK, D.; GAUCEL, S.; PERROT, N. Toward an integrated modeling of the dairy products transformations, a review of the existing mathematical models. Food Hydrocolloids, v. 27, p. 1-13, 2012.

HE, J.; MU, T. Application of an Artificial Neural Network for Predicting the Texture of Whey Protein Gel Induced by High Hydrostatic Pressure. CCTA2012: Computer and Computing Technologies in Agriculture VI, p. 118-125, 2013.

KLASSEN, T. Uso de redes neurais artificiais para a modelagem da temperatura e da retenção de água no processo de resfriamento de carcaças de frango por imersão. Dissertação (Mestrado em Engenharia Química), Universidade Estadual do Oeste do Paraná, 2008.

PERRECHIL, F. A.; BRAGA, A. L. M.; CUNHA, R. L. Interactions between sodium caseinate and LBG in acidified systems: Rheology and phase behavior. Food Hydrocolloids, v. 23, p. 2085-2093, 2009.

PERROT, N.; TRELEA, I. C.; BAUDRIT, C.; TRYSTRAM, G.; BOURGINE, P. Modelling and analysis of complex food systems: State of the art and new trends. Trends in Food Science and Technology, v. 22, p. 304-314, 2011.

PICONE, C. S. F., TAKEUCHI, K. P.; CUNHA, R. L. Heat-induced whey protein gels: Effects of $\mathrm{pH}$ and the addition of sodium caseinate. Food Biophysics, v. 6,p. 77-83, 2011.

RIBEIRO, K. O., RODRIGUES, M. I., SABADINI, E., \& CUNHA, R. L. Mechanical properties of acid sodium caseinate- $\kappa$-carrageenan gels: effect of co-solute addition. Food Hydrocolloids, v. 18, p. 71-79, 2004.

TAKEUCHI, K. P.; CUNHA, R. L. Influence of ageing time on sodium caseinate gelation induced by glucono- $\delta$-lactone at different temperatures. Dairy Science and Technology, v. 88 , p. 667-681, 2008. 